\title{
Empirical Study on the Performance of Merger of Tencent Merging Jingdong
}

\author{
Zehong Li ${ }^{1, a}$ \\ ${ }^{1}$ North China Electric Power University, \\ Baoding, China \\ a1043204896@qq.com
}

\author{
Yuanchun Xue ${ }^{1, b}$ \\ ${ }^{1}$ North China Electric Power University, \\ Baoding, China \\ bsuperxyc@139.com
}

\begin{abstract}
More and more M\&A cases are emerging in our country, the number and account are constantly flushing the record.What's more, the urban companies have begun to merge overseas ,especially for BAT(Baidu, Alibaba, Tencent).In 2014, Tencent has bid for a nationwide with its $\$ 21.4$ billion proposal to buy $15 \%$ shares of Jingdong.This article is written to calculate the M\&A performance in this case and evaluate the volatility of stock prices before and after the case.
\end{abstract}

Keywords: M\&A performance, event study method

\section{INTRODUCTION}

According to QingKe Research Center, 2014 was an important year for Internet industry with $\$ 27.51$ billion worth of transactions, jumped $922.7 \%$ than 2012. Also, the major buyers are still BAT.

About 317 M\&A case were announced in 2013,while 2014 is apparently bigger than last year.The famous cases have been the Baidu hopes to gain greater scale by buying 91online in a deal valued at \$19billion, Alibaba has bid for Youku \&Tudou at a price of $\$ 12.2$ billion, Tencent buy shares of 58city with $\$ 7.36$...More importantly, these 3 super major company have also seeking overseas companies. Baidu has buy Trustgo with $\$ 30$ million, which is an American online company, Alibaba has acquired ShopRunner with \$75 million, which is an express delivery company in America, Tencent has acquierd Activision Blizzard with \$14 billion. We can see the major market has been occupied with BAT, and we should come to the conclusion that by almost every measure, the $\mathrm{M} \& \mathrm{~A}$ time is coming.

Corporate boards and management teams have come to realize that a substantial move, like acquiring a major competitor or complementary business, is now see as necessary to gain target company`s control and operating as well as financing synergies.It is useful to improve both side`s management, and is also essential to lower cost and boost competitiveness. Shareholders and markets react quickly to acquisions, which reflect in stock prices.This article is mainly evaluate a classical cases of Tencent, which happened in 2014.

\section{M\&A Related Concept and Performance Theory}

M\&A include 2 meanings-- mergers and acquisitions, which also represent 2 different methods.The 2 methods are always used together internationally. Merger refers to a company taking various forms to acquire other company`s property, which will lead the mergerd company change or lose legal personality.Acquisition refers to a company (the acquirer) purchase another company (the reacquired company or the target company) part of or all stock assets with cash or stocks to gain the target company`s control. M\&A is a major way to capital operation and management.Mergers and acquisitions, can be divided into different types with different standards. For example, there has been Horizontal M\&A, Vertical M\&A, Conglomerate M\&A by relationship between companies, there also has been Purchasing Asset model, Absorbing Stock model, Holding model, Incremental Holding model, Merger in Stock Market, Volunteer Equity Transfer, Assets Replacement and Equity 
Replacement ect. by different realizing way.

The main method has been the long-term performance evaluation and the short-term performance evaluation. There are several derived method based on different financial theory point of view, such as event study method, factor analysis, non-financial indicators analysis, discounted cash flow method, the expert evaluation method, brainstorming, etc. Event study is the mainstream of the currently used in the empirical method. This method can clearly show how the M\&A events affect the stock price.Put the M\&A as a single event, through superior yield (Average Abnormal Return, AAR) and cumulative Abnormal returns (Cumulated Abnormal Return, CAR) to test the effect on the stock price fluctuation, then we can see how the event change shareholders` wealth. Superior yield is the part that more than normal (expected) yield, namely the AAR = real yields - normal returns. Normal rate of return refers to the right rate if the M\&A case didn`t happend.

Generally speaking, the operation of the event study method can be divided into the following steps: selecting study window, calculate events period sample returns and market returns, estimate the normal yield and calculate the event window of AAR, the interpretation of the empirical conclusions, etc. Specific steps are as follows:

(1). The selection of event window: in general, will announce the before and after the event information for a period of time is defined as the event period, it contains event and estimate the window two parts. Events refers to the period of continuous time window contains information announcement, usually in event bulletin for the center for the first time, the announcement date set for 0 days. Determine if the event window in order to achieve the incident to the full impact of stock price, its length can be set.During long may catch too much other information and data of irrelevant factors; During a short and may not be able to fully reflect the $m \& a$ information to the stock prices.

(2). Calculate event samples yield and market yields:

$$
\mathrm{r}_{\mathrm{i}, \mathrm{t}}=\left(\mathrm{P}_{\mathrm{i}, \mathrm{t}}-\mathrm{P}_{\mathrm{i}, \mathrm{t}-1}\right) / \mathrm{P}_{\mathrm{i}, \mathrm{t}-1}
$$

$$
\begin{aligned}
& \mathrm{R}_{\mathrm{i}, \mathrm{t}}=\ln \left(1+\mathrm{r}_{\mathrm{i}, \mathrm{t}}\right) \\
& \left.\mathrm{R}_{\mathrm{m}, \mathrm{t}}=\mathrm{P}_{\mathrm{m}, \mathrm{t}}-\mathrm{P}_{\mathrm{m}, \mathrm{t}-1}\right) / \mathrm{P}_{\mathrm{m}, \mathrm{t}-1} \\
& \mathrm{R}_{\mathrm{m}, \mathrm{t}}=\ln \left(1+\mathrm{r}_{\mathrm{m}, \mathrm{t}}\right)
\end{aligned}
$$

$r_{i, t}$ on behalf of a certain stock in trading day yield, $P_{i, t}$ on behalf of its shares in $\mathrm{t}$ trading day, $R_{i, t}$ on behalf of its continuous welfare yields on $\mathrm{t}$ day, $r_{m, t}$ on behalf of market yields in trading day, $P_{m, t}$ on behalf of the market index in t trading day, $R_{m, t}$ on behalf of the market continuous compound interest yields in $\mathrm{t}$ trading day. Normal yield estimation using common market model to estimate:

$$
A A R_{i, t}=R_{i, t}-\hat{R}_{i, t}
$$

Calculate the supernormal yield of the stock:

$$
C A R=a+b * R_{m, t}+\varepsilon_{i, t}
$$

\section{The Empirical Research}

\section{1. the Empirical case introduction}

Tencent [HK0700] is one of the largest Internet comprehensive service provider in China. Tencent started being active investment and merger and acquisition activity since 2010. Jingdong is China's largest proprietary type E-commerce enterprise. on March 10, 2014, Tencent acquire Jingdong 350 million ordinary shares, which accounts for $15 \%$ of the liquid share of Jingdong before its listingt. Jingdong and Tencent also signed the E-commerce overall strategic cooperation agreement.In the agreement,Tencent's Paipai C2C, QQ online affiliate associated company's registered capital, assets, business will transfer to Jingdong, Jingdong also get a little share of Yi Xun and the right of buying Yixun 
residual equity. This acquisition, caused a stir in the Internet industry at that time.

There are two main reasons to choose this case as reserach object: one is Tencent is listed in Hong Kong, and the Hong Kong securities market is relatively developed, the banker manipulation of probability is small, the volatility of the stock price less affected by banker; another reason has been that this case is just happened months ago, which made it a suitable case. We choose the event study as research method, for in the securities market, the M\&A effect often affect the share price only a period of time. As people say,there are no permanent positive and negative, in that way, short-term performance evaluation method is more appropriate in this case.

According to the event study method,we designated the announcement on March 10 as 0 days. We designated 30 working days before 0 days and 20 days after 0 days as the event window, namely [- 30, 20].We select 80 working days before 0 days to 30 working days before 0 days as estimated window, namely [- 80,-30]. Tencent[HK0700] share price data and the Hang Seng index are acquired from sina finance and economics. In this case,$[11.13,11.13]$ will be the estimate window, $[1.25,4.8]$ will be the event window. Matlab is used to calculate.

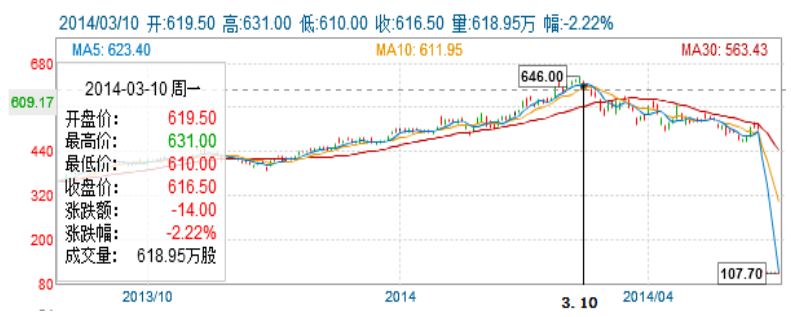

Fig.1 Tencent stock price trend during the merger

Fig. 1 is for Tencent's share price. We can see from the

figure that when Tencent announced to buy 15\% stake of

Jingdong on March 10, its share price reached a relative

peak (asterisk). In fact,before March 10,its share price has been in a rising trend. Considering the actual situation of message leakage (in fact, as early as January has news about this matter), the trend is normal. Then the downward trend in market prices show that the market began to gradually return to rational.

\subsection{Short-term performance of the results and analysis.}

According to statistical analysis by excel and matlab, it is concluded that if the acquisition does not occur, Tencent expected price(y) with the hang seng index(x) should be as follows:

$\mathrm{Y}=1.0366 * \mathrm{x}+0.0053$

Comparing with its actual price, we can draw the movements of AAR and CAR, as it shown in figure below:

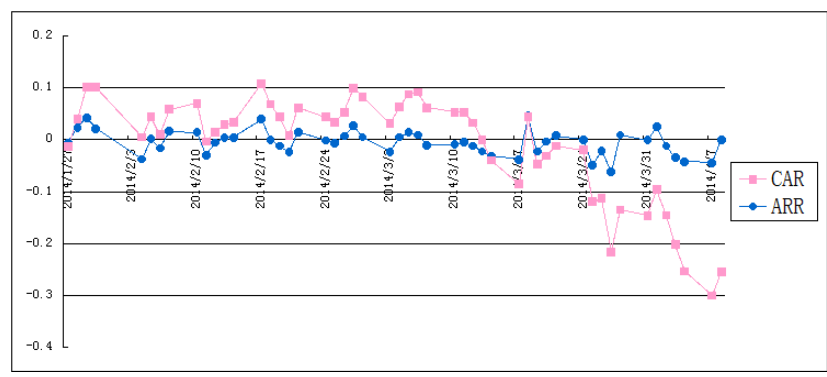

Fig.2 AAR and CAR trend during the merger

We can see from the Fig.2, that the AAR is in a rising trend with a few bouts of vloatility. In the 29 days before announcement, there are 19 days in which the AAR is above 0 (accounting for $65.52 \%$ of all days), with a mean of 0.002566 . The CAR also showed a trend of volatility, but is still above 0.Acquisition is a slow process, which suggests that the market are absorbing information in a long period of time, Tencent shares went well in this case,which can be see clearly in the charts. After looking at the reports before the acquisition, mostly critics hold the opinion that Tencent dump its Paipai business and brought pressure to bear on alibaba is a wise choice. While after the announcement ,the ARR 
benething 0 days has accounted for $71.43 \%$, with the average of 0.01486 . As a result, the CAR is gradually decrease. At the same time negative reports has appeared, which hold the opinion that the abandoning of Yi Xun and giving up the opportunity to compete against Jingdong is not worthful for Tencent.Then from the point of the stock market,there is no permant positive.So after the peak value of the stock pricecertaninly should have a period of consolidation.

As a result, we can see the acquisition has received positive ARR before announcement, which shows that the

before, and had been proved to be successful. Tencent could easily get access to resources in other field. Therefore, from a strategic point of view, the acquisition is favorable for Tencent and Jingdong.

\section{CONCLUSIONS}

This paper using the event study to calculate a classical m\&a case performance. The AAR before announcement is positive, which shows that the shareholders and market support for the merger. After the announcement ,the AAR went negative, which means the market is consolidated to rational. With more and more people are using the Internet and the strong support of shareholders and market support for the merger. While after the announcment, ARR gose negative, which means the marktet is consolidated to rational. Meanwhile, the media voice is closely related to the share price.

This case was looked as preparation work before listing for Jingdong, because just after the merger,Jingdong raised to $\$ 15.7$ billion for its selfvaluation,which means a lot for Jingdong`s listing in the same year,. At the same time, in the case of Tencent, similar mergers and acquisitions have already happened

national policy, the Internet industry reshuffle and M\&A will be pushed further.

\section{References}

[1] Mandelker,G. "Rish\&Return: The Case of Merging Firms", Journal of Financial Economics, 1974, 1, pp303-335

[2] Feng Genfu, Wu Linjiang, The Empirical Reserach of M\&A Performance of Listed Enterprises in China, Journal of Economic Reserach, 1999, 9

[3] Liu Yan, The Empirical Reserach of Cross-border M\&A of Listed Enterprises in China, Journal of Business Studies, 2011, 6, pp 106-111 